\title{
A retrospective review of the transfer of critically ill children to tertiary care in KwaZulu-Natal Province, South Africa
}

\author{
C Royal, ${ }^{1}$ MB ChB, FC Paed; N H McKerrow, ${ }^{1,2}$ MB ChB, BA, DCH (SA), FC Paed, MMed (Paed), PG Dip (Int Res Ethics) \\ ${ }^{1}$ Department of Paediatrics and Child Health, Nelson R Mandela School of Medicine, Faculty of Health Sciences, University of KwaZulu- \\ Natal, Durban, South Africa \\ ${ }^{2}$ Department of Health, KwaZulu-Natal, South Africa
}

Corresponding author: C Royal (candiceroyal@gmail.com)

\begin{abstract}
Background. Obtaining care for an acutely ill child in specialised paediatric services relies on referral from lower-level facilities. In South Africa, it is common practice for acutely ill children to be transported far distances by non-specialist teams with limited equipment, knowledge and skills.

Objectives. To describe the transfer of these children and to determine whether they deteriorate from the time of referral to the time of arrival at a tertiary centre. Furthermore, we sought to identify modifiable factors that might improve outcomes during resuscitation and transfer. Methods. The study was a retrospective review of emergency referrals of children aged 1 month - 12 years to Grey's Hospital paediatric ward or paediatric intensive care unit (PICU), from lower-level facilities in KwaZulu-Natal between January and June 2012. In conjunction with an assessment by the receiving clinician at Grey's Hospital, Triage Early Warning Signs (TEWS) scores were obtained during telephonic referral and compared with the TEWS score on arrival in order to determine if a deterioration had occurred.

Results. A total of 57 PICU referrals and 79 ward referrals were analysed. The mortality rate prior to transportation was $8.8 \%$. Mean transfer distance was $131 \mathrm{~km}$ and mean transfer time 9 hours. Advanced life support teams undertook transportation in $76.7 \%$ of PICU and $25 \%$ of ward transfers and few adverse events were reported in transfer logs. However, 31.5\% of PICU and 11.3\% of ward referrals required immediate resuscitation on arrival. When the TEWS scoring system was applied $78.5 \%$ of PICU and $30.4 \%$ of ward referrals fell into the 'very urgent' and 'emergency' categories. Conclusion. Pretransport and in-transit care failed to stabilise children and this may reflect lack of skill of attending healthcare workers, transport delays or illness progression. Interventions to improve resuscitation and transfer are needed, and the use of retrieval teams should be investigated.
\end{abstract}

S Afr J Child Health 2015;9(4):112-118. DOI:10.7196/SAJCH.2015.v9i4.913

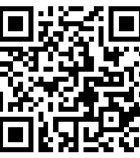

The centralisation of specialised services such as paediatric intensive care units (PICUs) relies on the support of a functional peripheral health service and appropriate referral system. In this context, the role of these peripheral services is the early recognition, stabilisation and safe transfer of critically ill children to the centralised service. The South African (SA) experience suggests that the peripheral health service has limited capacity ${ }^{[1]}$ to manage an acutely ill child, as evidenced by $34 \%$ mortality in children within the first 24 hours of admission to a health facility. ${ }^{[2]}$

Children are referred to higher-level facilities to access the skills, knowledge and resources needed to make a diagnosis or provide treatment. The practice of centralising paediatric intensive care services, specifically, has been associated with lower mortality rates and costs..$^{[3-6]}$ These intensive care units are able to provide high-quality care due to their familiarity with the management of seriously ill children. ${ }^{[7]}$

Children admitted to PICUs in SA have been shown to differ substantially from those in developed countries, tending to be younger and requiring management of infective illnesses. ${ }^{[8,9]}$ Late presentation and delayed referral of acutely ill children contribute to an increased disease severity at admission. ${ }^{[2]}$ Furthermore, it is common practice for acutely ill children to be transported far distances by non-specialist teams with limited equipment, knowledge and skills.

The pathways to care study in Cape Town evaluated 285 patients over 1 year from illness onset to PICU admission. ${ }^{[10]}$ Shortfalls in care were identified in $74 \%$ of cases. These shortfalls were grouped into four categories: identification of the critically ill child; resuscitation; transfer; and ICU access/flow management.

Walls et al's ${ }^{[11]}$ experience in Washington DC showed that $22 \%$ of paediatric patients referred from community hospitals to a central teaching hospital received suboptimal care prior to transport. Hatherill et al. ${ }^{[12]}$ reported a high incidence of transfer-related adverse events during transfers to Cape Town's Red Cross War Memorial Children's Hospital PICU, as did Goh et al. ${ }^{[6]}$ in Malayasia.

Our objective was to describe the journey of a critically ill child from referral to arrival at tertiary care, and to identify modifiable factors that could improve outcomes during the resuscitation and transfer process.

\section{Methods}

The study was a retrospective review of the medical records of children referred as emergency cases to Grey's Hospital, Pietermaritzburg, January - June 2012. Ethical approval was obtained from the University of KwaZulu-Natal Biomedical Research Ethics Committee.

Inclusion criteria were: $(i)$ age 1 month - 12 completed years; (ii) emergency referrals to the Paediatric Department of Grey's Hospital; and (iii) children referred to the paediatric medical service.

Exclusion criteria were: (i) neonates ( $<28$ days); (ii) elective referrals; (iii) internal referrals from within Grey's Hospital; and (iv) children referred to the surgical service.

All requests for transfer to the Paediatric Department in Grey's Hospital are assessed by a registrar or medical officer, recorded in a call register and then discussed with a consultant paediatrician prior to the acceptance or refusal of the request. The call register is a standardised, comprehensive questionnaire that covers resuscitation and vital signs, and prompts advice for further resuscitation (Appendix 1). The register was reviewed to identify cases for inclusion in the study. The clinical records were retrieved and data extracted from the case notes, transfer logs and referral letters. SPSS version 18 (IBM, USA) was used for statistical analysis. 
Two methods were used to assess the outcome of patient transfers:

- Method 1: The clinical assessment of the receiving clinician on arrival of the child. Children were assessed as stable or unstable. They were deemed unstable on arrival if they required any one of the following: intubation and ventilation, correction of shock, abortion of seizures or the correction of hypoglycaemia (whole blood glucose $<3 \mathrm{mmol} / \mathrm{L}$ ) or hypothermia (axillary temperature $<35^{\circ} \mathrm{C}$ ).

- Method 2: Each child was assigned a triage category by identifying clinical signs and calculating the Triage Early Warning Signs (TEWS) score at the time of referral and on arrival (Appendix 2). TEWS is a composite, age-appropriate physiological scoring system that is the basis of the SA Triage Scale. ${ }^{[13]}$ The use of TEWS has been validated in the Western Cape as a sensitive and specific method of identifying potentially seriously ill children. ${ }^{[13,14]}$ The process of triaging a patient telephonically requires a rapid, efficient assessment, akin to the triaging of a patient in the accident and emergency department. TEWS scoring provides a rapid, validated assessment of patient stability with data that are readily available retrospectively. Based on the TEWS scores, patients were grouped into emergency, very urgent, urgent and routine priority categories. Children who had a documented emergency sign such as active convulsions or oxygen saturations $<92 \%$ were placed in the emergency category. Children who arrived on a ventilator were not scored.

The Wilcoxon signed rank test was used to determine the correlation of patient diagnosis by referring and receiving clinicians. The $t$-test was used to evaluate a change in TEWS scores between the time of referral and time of arrival.

\section{Results}

During the 6-month study period, 229 children were accepted as acute referrals to Grey's Hospital. Of these, 93 children were excluded from the study - 31 because their primary problem was surgical and a further 62 due to missing or incomplete clinical records.

A total of 136 children were enrolled in the study - 57 acute referrals to the PICU and 79 referrals to the paediatric wards. Twelve of the PICU referrals demised prior to transfer and 124 were admitted to Grey's Hospital. A profile of these children is presented in Table 1.

Children admitted to the PICU were of a younger median age than those admitted to the wards. The gender split was similar within the two groups. Children admitted to the PICU were more likely to be of normal weight and unknown HIV status, while children referred to the wards were likely to have had a longer pretransfer stay and thus opportunity for their HIV status to be determined. HIV infection is not an exclusion criterion for admission to the PICU.

Children referred to both the PICU and the paediatric wards generally had more than one problem identified by the referring doctor. The most common problem referred to the PICU was pneumonia (46.9\%), followed by gastrointestinal problems (18.1\%), which was diarrhoeal disease in $17 \%$ of the cases, and to the paediatric wards was a neurological problem (32.8\%) (Table 2). Seizures were the most common primary problem identified at the time of referral to the wards (12.7\%). The Wilcoxon signed rank test revealed no significant differences between the primary problem identified at the referring and referral centers (PICU $p=0.108$; wards $p=0.789$ ).

Indication for referral to the PICU was for treatment in $97.8 \%$ of cases, $51.1 \%$ specifically for ventilation. A need for radiological investigations to reach a diagnosis was the indication for referral for the remaining case. In contrast, the indication given by the referring centre for children referred to the paediatric wards was for assistance in making a diagnosis in all 79 cases. Further investigation was required in $58.2 \%$ of the children, while $41.8 \%$ required a specialist opinion.

The referring clinician was an intern, community service officer or medical officer in $78.9 \%$ of PICU referrals and $94 \%$ of ward referrals. For $20 \%$ of referrals to the PICU and $18 \%$ to the wards, transfer followed on-site assessment by a paediatrician. Prior to transportation, $8.8 \%$ of children demised; all of these had been referred to the PICU. Distances between facilities relied on Department of Health data on the distance of each facility to its head office, which is $4 \mathrm{~km}$ from Grey's Hospital. The distance travelled averaged $131.5 \mathrm{~km}$, with a range of $4.4 \mathrm{~km}$ to $424.9 \mathrm{~km}$ and a median of $110 \mathrm{~km}$. The total time to transfer a child, from acceptance for transfer and arrival at Grey's Hospital, is presented in Table 3. Of note is that the mean transfer time to the PICU was longer than to the wards.

Characteristics of the transfers are presented in Table 4. All transfers to the wards and $92.5 \%$ of PICU transfers were undertaken by road. Advanced life support (ALS) teams were used for $76.7 \%$ of PICU and $25 \%$ of ward transfers.

Table 1. Population characteristics

\begin{tabular}{lll}
\hline & PICU $(n=45)$ & Wards $(n=79)$ \\
\hline Age (months), median & 6 & 19 \\
Gender (male), $n(\%)$ & $23(51.1)$ & $46(58.2)$ \\
Nutritional status $(n=106)$ & & \\
$\quad$ Normal, $n(\%)$ & $30(73.2)$ & $33(50.0)$ \\
Underweight for age, $n(\%)$ & $11(26.8)$ & $32(48.5)$ \\
Overweight for age, $n(\%)$ & $0(0)$ & $1(1.5)$ \\
HIV status $(n=114)$ & & \\
Infected, $n(\%)$ & $4(9.3)$ & $15(21.1)$ \\
Uninfected, $n(\%)$ & $11(25.6)$ & $28(39.4)$ \\
Unknown, $n(\%)$ & $28(65.1)$ & $28(39.4)$
\end{tabular}

Table 2. Referral diagnosis

\begin{tabular}{lll}
\hline Patient problem & PICU $(n=88), n(\%)$ & Wards $(n=131), n(\%)$ \\
\hline Respiratory & $41(46.9)$ & $25(19.1)$ \\
Neurological & $9(10.2)$ & $43(32.8)$ \\
Cardiac & $4(4.5)$ & $14(10.7)$ \\
Gastrointestinal & $16(18.1)$ & $14(10.7)$ \\
Renal & 0 & $10(7.6)$ \\
Haematological & 0 & $4(3.0)$ \\
Metabolic & $1(1.1)$ & 0 \\
Infective & 0 & $15(11.5)$ \\
Other & $17(19.3)$ & $6(4.6)$
\end{tabular}

Table 3. Transfer times and distances

\begin{tabular}{lll}
\hline & PICU & Wards \\
\hline Transfer time $(\mathrm{h})$ & & \\
Range & $3.80-18.75$ & $1.5-25.5$ \\
Mean & 9.5 & 8.6 \\
Mode & 8.6 & 4.0 \\
Transfer distance $(\mathrm{km})$ & & \\
Range & $4.4-424.9$ & $4.4-271.0$ \\
Mean & 130 & 133 \\
Median & 110 & 110
\end{tabular}


No children being transported to the wards experienced problems in transit, compared with $15.5 \%$ of those destined for the PICU. The majority of these problems related to modalities of care. Children were ventilated during transfer in $28 \%$ of referrals to PICU and complications were experienced en route in $12.5 \%$.

At the time of referral request, $82.4 \%$ of children referred to the PICU were unstable compared with $15 \%$ referred to the wards. Over half of the children required respiratory support while $24.4 \%$ required correction of shock. This resuscitation appears to have been short-lived, as on arrival $78.5 \%$ of children admitted to the PICU and $30.4 \%$ to the wards fell into the 'very urgent' and 'emergency' categories when TEWS was applied. A comparison of these scores reveals no statistically significant difference (PICU $p=0.202$; wards $p=1.810)$. The mean change in TEWS was -0.52 for the PICU and -0.6 for ward referrals. Table 5 depicts the TEWS score at time of requesting transfer, subsequent resuscitation prior to transfer and the TEWS score on arrival at Grey's Hospital.

The subjective assessment on arrival by the receiving clinician revealed that $31.5 \%$ and $11.3 \%$ of referrals to the PICU and the wards, respectively, required immediate resuscitation. On arrival at Grey's Hospital, $14 \%$ of children referred to the PICU required intubation

Table 4. Characteristics of transfers

\begin{tabular}{lll}
\hline & PICU & Wards \\
\hline Method of transportation (\%) & & \\
Road & 92.5 & 100 \\
Air & 7.5 & 0 \\
Expertise undertaking transportation (\%) & & \\
ALS & 76.7 & 25.0 \\
Basic life support & 23.3 & 75.0 \\
Problems in transit, $n(\%)$ & & \\
Nil & $38(84.4)$ & $79(100)$ \\
Required intubation & $2(4.4)$ & 0 \\
Lost intravascular access & $3(6.7)$ & 0 \\
Seizures in transit & $1(2.2)$ & 0 \\
Intercostal drain dislodged & $1(2.2)$ & 0
\end{tabular}

and ventilation, $17.5 \%$ were assessed to be shocked and $5 \%$ had no intravenous access.

\section{Discussion}

Every day, children are referred from lower-level facilities to specialised paediatric services, yet little is known about the effect of such referrals on the acutely ill child in developing countries. Evidence from the developed world confirms the value of a specialised transfer process that includes the appropriate pre- and intratransfer care provided by specialised staff. ${ }^{[15,16]}$ This study was conducted in a health service without specialised transfer teams and in a context characterised by unstable children, high pretransfer mortality, prolonged transfer time and high rates of adverse events in transit.

\section{Pretransport care}

Pretransport care is essential to ensuring a safe paediatric referral The $8.8 \%$ of referrals who died before transfer is a concern. These children had a similar profile to those who were transferred. Most had pneumonia and a third of the deaths occurred at the time of intubation. These deaths could be the result of multiple factors, including: advanced disease, poor care and limited skills at the referring facility, especially in paediatric intubation; or transport delays. At the time of this study the inpatient death rate for children $<5$ years was $5.2 \%$ in KwaZuluNatal. ${ }^{[17]}$ The discrepancy between these figures underlines that the children who are being referred represent an at-risk group.

Resuscitation at the referring facility was required in 70 (51\%) of all referrals, and 34 children, three of whom were initially referred to the paediatric wards, required intubation and ventilation prior to transfer. This failure of referring clinicians to appreciate the unstable condition of their patient reflects the lack of confidence and competencies in the ability to care for critically ill children at a district facility. These concerns have been cited in the South African study by Nkabinda et al. ${ }^{[18]}$ who reviewed community service medical officers' experience of working in district hospitals in KwaZulu-Natal and identified paediatric resuscitation and intubation as a skill domain in which confidence was lacking. We propose interventions to improve resuscitation and intubation skills in the periphery.

Respiratory problems accounted for $46.9 \%$ of referrals to the PICU. This finding is in line with the developed world and reiterates the need for pretransport care to be undertaken by those experienced in paediatric ventilation. ${ }^{[19]}$ Only $20 \%$ of PICU referrals had been seen by a paediatrician. Incentives to attract specialists to outlying areas need to be explored.

Table 5. TEWS and resuscitation at referring centre

\begin{tabular}{|c|c|c|c|c|}
\hline & \multicolumn{2}{|c|}{ PICU } & \multicolumn{2}{|l|}{ Wards } \\
\hline & TEWS at time of referral & TEWS on arrival & TEWS at time of referral & TEWS on arrival \\
\hline \multicolumn{5}{|l|}{ TEWS score } \\
\hline Mean (SD) & $6.43(1.70)$ & $5.91(2.15)$ & $4.20(1.91)$ & $3.6(2.29)$ \\
\hline Median & 10 & 6 & 4 & 3 \\
\hline Routine, \% & 5.4 & 7.1 & 24.6 & 42.0 \\
\hline Urgent, \% & 13.5 & 14.3 & 35.1 & 27.5 \\
\hline Very urgent, \% & 24.3 & 32.1 & 21.1 & 11.6 \\
\hline Emergency, \% & 56.8 & 46.4 & 19.3 & 18.8 \\
\hline \multicolumn{5}{|c|}{ Resuscitation at referring centre, $n(\%)$} \\
\hline Nil & $9(20.1)$ & & $67(84.8)$ & \\
\hline Ventilation & $31(56.3)$ & & $3(3.7)$ & \\
\hline Correction of shock & $11(24.4)$ & & $3(3.7)$ & \\
\hline Other & $5(11.1)$ & & $6(7.5)$ & \\
\hline
\end{tabular}




\section{In-transit care}

Transportation occurred almost exclusively by road and time delays were a major problem, with a mean delay of 9 hours from time of referral to time of arrival. This may be attributed to the lack of availability of Emergency Medical Service crews, especially those with ALS skills, as well as ambulances with appropriate equipment such as transport ventilators. Transfer distances occurred over relatively long distances, with a mean transfer distance for PICU referrals of $130 \mathrm{~km}$ in contrast to $31 \mathrm{~km}$ reported in England and Wales. ${ }^{[15]}$

Staff with skills limited to basic life support were responsible for in-transit care for $75 \%$ of ward transfers and $25 \%$ of PICU transfers. A study in the UK reported $81 \%$ use of retrieval teams for PICU transfers. ${ }^{[15]}$ Although this figure is not dissimilar to the use of ALS crews used in our study, it must be recognised that the UK retrieval teams include a doctor proficient in the care of critically ill paediatric patients, a skills set that an ALS-trained paramedic does not necessarily have.

On review of transfer logs, $15.6 \%$ of PICU referrals reported problems during transportation although no problems were reported from the ward referrals. International studies vary with regard to the incidence of adverse events in transfer, from $87.5 \%$ with nonspecialised teams ${ }^{[6]}$ to $4 \%$ with retrieval teams. ${ }^{[15]}$ The paucity of adverse events reported coupled with the high proportion of both PICU and ward patients falling into the emergency and very urgent groups by TEWS scoring suggests a lack of insight in those undertaking these transfers.

\section{Outcome of the referral}

Although resuscitation occurred at referring facilities, on arrival at Grey's Hospital the majority of children referred to the PICU and almost a third referred to the wards still fell into the very urgent and emergency categories of triage acuity. Additionally, 31.5\% of children referred to the PICU and $11.3 \%$ referred to the wards required immediate resuscitation. Children's vital signs did not improve toward physiological ranges during referral as represented by the lack of statistically significant difference between TEWs at referral and on arrival. Pretransport and in-transit care failed to stabilise children and this may reflect lack of skill of attending healthcare workers, transport delays or illness progression.

\section{Study limitations}

As this was a retrospective study, incomplete clinical records and inadequate documentation was a limitation. This is notable in that not all children could be ascribed a TEWS score at base and/or on arrival owing to a lack of recording or measuring of vital signs.

\section{Recommendations}

From this study it is apparent that paediatric referrals are hampered by time delays and that pretransport and in-transit care is suboptimal. A need for improved competencies in the management of the acutely ill child at district level hospitals is highlighted. Further research is required to assess the feasibility and the potential benefit of the institution of retrieval teams in a developing world setting, particularly for the transfer of patients to the PICU.

\section{Conclusion}

In SA's current public health system, paediatric specialist care and intensive care specifically is centralised to tertiary institutions, with a resultant reliance on a referral system. The drainage area of tertiary facilities varies but often encompasses multiple district facilities with a large geographic distribution. Attempts to bring specialist paediatric services to district-level facilities are underway but are unlikely to be realised in the short term. Moreover, critical care in a tertiary PICU remains preferable. Child Healthcare Problem Identification Programme (Child PIP) data has repeatedly identified lack of access to high care or ICU beds as a modifiable factor in child deaths. Advances such as telemedicine have a role in connecting district facilities with specialists, but are less useful in the care and stabilisation of an acutely ill child.

This study has shown that paediatric referrals in KwaZulu-Natal are both inefficient and take place over long distances. Acutely ill children are not successfully stabilised at base or during transfer, resulting in a higher morbidity and mortality than in the developed world. The use of retrieval teams requires urgent investigation if there is to be an improvement in paediatric care and a reduction in childhood mortality.

\section{References}

1. Department of Health, South Africa. The First Triennial Report of the Committee on Morbidity and Mortality in Children under 5 years (CoMMiC), April 2011. www.health.gov.za/docs/reports/2011/morbreport.pdf (accessed on 20 February 2014)

2. Stephen CR, Bamford LJ, Patrick ME, Wittenberg DF, eds. Saving Children 2009: Five years of Data. A sixth survey of child healthcare in South Africa. Pretoria: Tshepesa Press, MRC, CDC, 2009.

3. Pearson G, Shann F, Barry P, et al. Should paediatric intensive care be centralized? Trent versus Victoria. Lancet 1997;349(9060):1213-1217. [http:// dx.doi.org/10.1016/S0140-6736(96)12396-5]

4. Pollack MM, Alexander SR, Clarke N, Ruttimann UE, Tesselaar HM. Improved outcomes from tertiary center paediatric intensive care: A statewide comparison of tertiary and nontertiary care facilities. Crit Care Med 1991;19(2):150-159. [http://dx.doi.org/10.1097/00003246-199102000-00007 ]

5. Edwards ED, Fardy CH. Which children need to be transferred to the paediatric intensive care unit? Paediatr Child Health 2007;17(7):295-299. [http://dx.doi. org/10.1016/j.paed.2007.04.002 ]

6. Goh AY, Abdel-Latif Mel A, Lum LC, Abu-Bakar MN. Outcome of children with different accessibility to tertiary pediatric intensive care in a developing country--a prospective cohort study. Intensive Care Med 2003;29(1):97-102.

7. Bennett NR. Transfer of the critically ill child. Current Paediatrics 1995;5(1):4-9.

8. Morrow BM, Argent AC, Jeena PM, Green RJ. Guidelines for the diagnosis, treatment and prevention of paediatric ventilator-associated pneumonia. S Afr Med J 2009;99(4):255-267.

9. Delport SD, Brisley T. Aetiology and outcome of severe community-acquired pneumonia in children admitted to a paediatric intensive care unit. S Afr Med J 2002, 92(11):907-911.

10. Hodkinson P, Argent A, Wallis L. Paediatric emergency and critical care: Learning points and possible interventions from a longitudinal study of paediatric emergency care and referral pathways. www.eci-sa.org/faculty/ hodkinson/pathways-to-care (accessed 20 January 2015).

11. Walls TA, Chamberlain JM, Strohm-Faber J, Klein BL. Improving pretransport care of emergency pediatric patients: An assessment of referring hospital care. Pediatr Emerg Care 2010;26(8):567-570. [http://dx.doi.org/10.1097/ PEC.0b013e3181ea71f8]

12. Hatherill M, Waggie Z, Reynolds L, Argent A. Transport of critically ill children in a resource-limited setting. Intensive Care Med 2003;29(9):1547-1554. [http://dx.doi.org/10.1007/s00134-003-1888-7]

13. Twomey M, Cheema B, Buys $H$, et al. Vital signs for children at triage: A multicenter validation of the revised South African Triage Scale (SATS) for children. S Afr Med J 2013;103(5):304-308. [http://dx.doi.org/10.7196/ SAMJ.6877]

14. Cheema B, Stephen C, Westwood A. Paediatric triage in South Africa. S Afr J Child Health 2013;7(2):43-45. [http://dx.doi.org/10.7196/sajch.585]

15. Ramnarayan P, Thiru K, Parslow RC, Harrison DA, Draper ES, Rowan KM. Effects of specialist retrieval teams on outcomes in children admitted to paediatric intensive care units in England and Wales: A retrospective cohort study. Lancet 2010;376(9742):698-704. [http://dx.doi.org/10.1016/S01406736(10)61113-0]

16. Stroud MH, Tautman MS, Meyer K, et al. Pediatric and neonatal interfacility transportation: Results from a national consensus conference. Pediatrics 2013;132(2):359-366. [http://dx.doi.org/10.1542/peds.2013-0529]

17. District Health Information System (DHIS) Database. National Department of Health. http://hisp.org/ (accessed September 2014).

18. Nkabinda TC, Ross A, Reid S, Nkwanyana NM. Internship training adequately prepares South African medical graduates for community service - with some important exceptions. S Afr Med J 2013;103(12): 930-934. [http://dx.doi. org/10.7196/SAMJ.6702]

19. Ajizian SJ, Nakagawa TA. Interfacility transfer of the critically ill pediatric patient. Chest 2007;132(4):1361-1367. [http://dx.doi.org/10.1378/chest.07-0222] 


\section{Monitoring \& handover sheet for paediatric transfers}

Date:

(to be completed by referring and receiving doctors starting at time of referral)

Time:

Patient Name:

Date of Birth:

DoA:

DoT:

1) REFERRING AND RECEIVING INFORMATION

\begin{tabular}{|l|l|l|l|l|l|}
\hline & \multicolumn{1}{|c|}{ Hospital } & Ward & & Doctor & \\
\hline Referring & & & Junior: & & \\
\hline & & & Senior: & & \\
\hline Receiving & & Junior: & & \\
\hline
\end{tabular}

2) Caregiver information
Accompanying
caregiver:
Relationship:
Contact number:

3) NUTRITION

\begin{tabular}{|c|c|c|c|c|c|c|cc}
\hline OWFA & Normal & UWFA & Marasmus & Kwashiorkor & M-K & Unknown & Weight: _ \\
\hline
\end{tabular}

4) HIV

\begin{tabular}{|r|c|c|c|c|c|c|c|}
\hline Laboratory test & Negative & Exposed & Infected & No result & $\begin{array}{c}\text { Not tested } \\
\text { (but indicated) }\end{array}$ & $\begin{array}{c}\text { Not tested } \\
\text { (not indicated) }\end{array}$ & Unknown \\
\hline Clinical & Stage I & Stage II & Stage III & Stage IV & $\begin{array}{c}\text { Not staged } \\
\text { (but indicated) }\end{array}$ & $\begin{array}{c}\text { Not staged } \\
\text { (not indicated) }\end{array}$ & Unknown \\
\hline ARV & Current & \multicolumn{2}{|c|}{ Ever } & Never (but indicated) & Never (not indicated) & Unknown \\
\hline
\end{tabular}

5) CURRENT CONDITION (CIRCLE APPLICABLE) TIME:

\begin{tabular}{|r|c|l|l|c|}
\hline Vitals & Temp: & PR: & RR: & Sats: \\
\hline Airway & Critical & Narrow & Normal \\
\hline Breathing & Needs IPPV & Needs oxygen & Hyperventilation & Normal \\
\hline Circulation & Shock (Cap refill > 3s) & Hypovolaemia & Hypervolaemia & Normal \\
\hline Consciousness (AVPU) & Unconscious & Response to Pain & Response to Voice & Alert \\
\hline Convulsions & In hospital & Before arrival & Past & Never \\
\hline Dehydration & $10 \%$ & $5 \%$ & Oedema & Normal \\
\hline IMCI classification & "Red" & "Yellow" & & "Green" \\
\hline Infection & SIRS ("toxic shock") & Needs IV agent & Needs oral agent & No \\
\hline
\end{tabular}

6) SIGNIFICANT BIOCHEMICAL PROBLEMS (CIRCLE APPLICABLE)

\begin{tabular}{|l|l|l|l|l|l|l|l|}
\hline Hypoxia (Sats in air__ & Hypoglycaemia & $\mathrm{pH}<7.2$ & $\mathrm{~K}^{+}<2.0$ & $\mathrm{~K}^{+}>6$ & $\mathrm{Na}^{+}<120$ & $\mathrm{Na}^{+}>150$ & Albumin $<20$ \\
\hline
\end{tabular}

\section{7) REASON FOR TRANSFER OR NON-ACCEPTANCE}

Accepted(circle applicable):

Main diagnosis / problem:

Other diagnoses / problems:

Prognosis for survival:

Prognosis for normal outcome:

Main reason for transfer / non acceptance

8) URGENT MANAGEMENT

\begin{tabular}{|r|l|l|}
\hline & \multicolumn{1}{|c|}{ Specific Rx (circle or state) } & \multicolumn{1}{c|}{ Other Rx } \\
\hline Airway & ETT / oral airway / none & Oxygen delivery: \\
\hline Breathing & IPPV / Bag / Spontaneous & Oxygen monitoring: \\
\hline Circulation/Shock & Intra-osseous / peripheral IV / central IV / none & Volume expand: \\
\hline Dehydration & IV / Oral & $1 / 2$ DD / ORS: \\
\hline Consciousness & Protect airway: & Coma position: \\
\hline Infection & IV antibiotic stat: & Steroid / antipyretic: \\
\hline
\end{tabular}

9) Pain Assessment

No pain

Mild pain

Moderate pain

Severe pain
YES

NO

ICD 10

Good

Good

Indeterminate

Guarded

Guarded 
Appendix 1 (cont.). Paediatric monitoring and handover sheet

10) ONGOING MONITORING AND RESPONSIBILITY WHILE AWAITING EMRS

\begin{tabular}{|c|c|c|c|c|c|c|c|c|c|c|c|c|c|}
\hline & \multicolumn{4}{|c|}{ Name } & \multicolumn{5}{|c|}{ Rank } & \multicolumn{4}{|c|}{ Contact number } \\
\hline \multicolumn{14}{|l|}{ Doctor } \\
\hline \multicolumn{14}{|l|}{ Nurse } \\
\hline Time & Temp & $\begin{array}{c}\text { Heart } \\
\text { rate }\end{array}$ & $\begin{array}{c}\text { Resp } \\
\text { rate }\end{array}$ & Sats & $\mathrm{FiO}_{2}$ & $\begin{array}{c}\mathrm{O}_{2} \\
\text { device }\end{array}$ & $\begin{array}{l}\text { IV site } \\
\text { secure }\end{array}$ & $\begin{array}{c}\text { IV } \\
\text { control } \\
\text { device }\end{array}$ & IV rate & $\begin{array}{l}\text { AVPU } \\
\text { score }\end{array}$ & BP & Gluc. & Sign \\
\hline & & & & & & & & & & & & & \\
\hline & & & & & & & & & & & & & \\
\hline & & & & & & & & & & & & & \\
\hline & & & & & & & & & & & & & \\
\hline & & & & & & & & & & & & & \\
\hline & & & & & & & & & & & & & \\
\hline & & & & & & & & & & & & & \\
\hline $\begin{array}{c}\text { On transfer } \\
\text { to } \\
\text { ambulance }\end{array}$ & & & & & & & & & & & & & \\
\hline
\end{tabular}

11) Problems arising and their PLANS While AWAiting EMRS

\begin{tabular}{|c|c|c|c|}
\hline Problem & Plan & Discussed with & Verified by \\
\hline & & & \\
\hline & & & \\
\hline
\end{tabular}

12) Patient Transport information

\begin{tabular}{|c|c|c|c|c|c|c|}
\hline Time accepted & $\begin{array}{c}\text { Receiving } \\
\text { Hospital }\end{array}$ & Doctor & Rank & Telephone & Plan \\
\hline Time EMRS called & $\begin{array}{c}\text { EMRS Ops } \\
\text { Centre }\end{array}$ & Operator & Designation & Telephone & Plan \\
\hline $\begin{array}{c}\text { Time of EMRS } \\
\text { arrival }\end{array}$ & $\begin{array}{c}\text { Ambulance } \\
\text { type }\end{array}$ & Paramedic & Designation & Telephone & Sign \\
\hline $\begin{array}{c}\text { Time of departure, } \\
\text { AND receiving } \\
\text { hospital notified }\end{array}$ & $\begin{array}{c}\text { Receiving } \\
\text { Hospital }\end{array}$ & Doctor & Rank & Telephone & Plan \\
\hline $\begin{array}{c}\text { Time of arrival at } \\
\text { receiving hospital }\end{array}$ & Receiving Ward & Doctor & Rank & Telephone & Sign \\
\hline & & & & Plan & Sign \\
\hline
\end{tabular}

13) Patient handover

\begin{tabular}{|c|c|c|c|c|c|c|}
\hline \multicolumn{2}{|c|}{} & \multicolumn{2}{c|}{ Handed over by } & \multicolumn{2}{c|}{ Received by } & Designation \\
\hline Time & $\begin{array}{c}\text { Handover Point } \\
\text { Referring hospital to } \\
\text { EMRS }\end{array}$ & Name & Designation & Name & Sign \\
\hline & $\begin{array}{c}\text { EMRS to receiving } \\
\text { hospital }\end{array}$ & & & & & \\
\hline
\end{tabular}

14) Caregiver Plan

\begin{tabular}{|c|c|c|c|c|c|}
\hline Name & Relationship & $\begin{array}{c}\text { Contact } \\
\text { number }\end{array}$ & Breastfeeding & Well/sick & $\begin{array}{c}\text { Plan for transport to receiving } \\
\text { hospital }\end{array}$ \\
\hline & & & $y / n$ & & \\
\hline
\end{tabular}

\section{5) OUTCOME}

\begin{tabular}{|c|c|c|c|c|c|c|}
\hline $\begin{array}{c}\text { Alive \& not } \\
\text { transferred }\end{array}$ & $\begin{array}{c}\text { Died \& not } \\
\text { transferred }\end{array}$ & $\begin{array}{c}\text { Died awaiting } \\
\text { EMRS }\end{array}$ & Died in transit & $\begin{array}{c}\text { Died within 24 } \\
\text { hours of } \\
\text { transfer }\end{array}$ & $\begin{array}{c}\text { Died beyond 24 } \\
\text { hours of } \\
\text { transfer }\end{array}$ & $\begin{array}{c}\text { Alive and } \\
\text { transferred back } \\
\text { to referring } \\
\text { hospital }\end{array}$ \\
\hline
\end{tabular}

NB: this does not replace the usual referral letter containing ALL relevant clinical details; use the 'Paediatric Discharge/Referral Letter' proforma 


\begin{tabular}{|c|c|c|c|c|c|c|c|c|c|}
\hline \multicolumn{10}{|c|}{ Appendix 2. TEWS scoring } \\
\hline \multicolumn{10}{|c|}{ YOUNGER CHILD ( $<3$ years) TEWS } \\
\hline VALUE & & 3 & 2 & 1 & 0 & 1 & 2 & 3 & SCORE \\
\hline & Mobility & & & & $\begin{array}{l}\text { Normal } \\
\text { for age }\end{array}$ & & $\begin{array}{c}\text { Unable to } \\
\text { move as } \\
\text { normal }\end{array}$ & & \\
\hline & RR (/min) & $\begin{array}{c}\text { Less than } \\
70\end{array}$ & $20-25$ & & $26 \cdot 39$ & & $40-49$ & $\begin{array}{l}50 \text { or } \\
\text { more }\end{array}$ & \\
\hline & $\mathrm{HR}(/ \mathrm{min})$ & \begin{tabular}{|c|} 
Less than \\
70 \\
\end{tabular} & $70 \cdot 79$ & & $\begin{array}{l}80- \\
130\end{array}$ & & $131 \cdot 159$ & $\begin{array}{l}160 \text { or } \\
\text { more }\end{array}$ & \\
\hline & $\operatorname{Temp}\left({ }^{\circ} \mathrm{C}\right)$ & & $\begin{array}{l}\text { Feels cold } \\
\text { Under } 35\end{array}$ & & $\begin{array}{l}35 . \\
38.4\end{array}$ & & $\begin{array}{l}\text { Feels hot } \\
\text { Over } 38.4\end{array}$ & & \\
\hline & AVPU & & & & Alert & $\begin{array}{l}\text { Reacts to } \\
\text { Voice }\end{array}$ & $\begin{array}{c}\text { Reacts to } \\
\text { Pain }\end{array}$ & $\begin{array}{c}\text { Unrespon- } \\
\text { sive }\end{array}$ & \\
\hline & Trauma & & & & No & Yes & & & \\
\hline \multicolumn{7}{|c|}{ Younger than 3 years $/$ shorter than $95 \mathrm{~cm}$} & & TOTAL & \\
\hline \multicolumn{10}{|c|}{ OLDER CHILD ( $>3$ years) TEWS } \\
\hline VALUE & & 3 & 2 & 1 & 0 & 1 & 2 & 3 & SCORE \\
\hline & Mobility & & & & $\begin{array}{l}\text { Normal } \\
\text { for age }\end{array}$ & & $\begin{array}{l}\text { Unable to } \\
\text { walk as } \\
\text { normal }\end{array}$ & & \\
\hline & $\operatorname{RR}(/ \mathrm{min})$ & $\begin{array}{c}\text { Less than } \\
15\end{array}$ & $15 \cdot 16$ & & $17 \cdot 21$ & $22 \cdot 26$ & $\begin{array}{l}27 \text { or } \\
\text { more }\end{array}$ & & \\
\hline & HR (/min) & \begin{tabular}{|c|} 
Less than \\
60
\end{tabular} & $60 \cdot 79$ & & $80-99$ & $100-129$ & $\begin{array}{l}160 \text { or } \\
\text { more }\end{array}$ & & \\
\hline & Temp $\left({ }^{\circ} \mathrm{C}\right)$ & & $\begin{array}{l}\text { Feels cold } \\
\text { Under } 35\end{array}$ & & $\begin{array}{l}35 . \\
38.4\end{array}$ & & $\begin{array}{l}\text { Feels hot } \\
\text { Qver } 38.4\end{array}$ & & \\
\hline & AVPU & & Confused & & Alert & $\begin{array}{l}\text { Reacts to } \\
\text { Voice }\end{array}$ & $\begin{array}{c}\text { Reacts to } \\
\text { Pain }\end{array}$ & $\begin{array}{c}\text { Unrespon- } \\
\text { sive }\end{array}$ & \\
\hline & Trauma & & & & No & Yes & & & \\
\hline \multicolumn{7}{|c|}{$3-12$ years old $/ 95-150 \mathrm{~cm}$ tall } & & TOTAL & \\
\hline
\end{tabular}

